\title{
A COMPARISON OF PROJECT ALLIANCING AND LEAN CONSTRUCTION
}

\author{
Brendan K. Young ${ }^{1}$, Ali Hosseini ${ }^{2}$, and Ola Lædre ${ }^{3}$
}

\begin{abstract}
As the adoption of both alliancing and lean in the construction industry has started becoming more prevalent, knowledge of the alignment of Lean Construction with alliancing could be valuable to practitioners looking at adopting lean project delivery. This paper contributes to addressing this issue by providing insight into the relationship between the alliancing project delivery method and Lean Construction project delivery through the review of a literature review, interviews and a document study. A major driver of alliancing is to deliver value for money to the client, so it comes as a surprise that, to this date, alliancing has yet to fully capitalize on the Lean Construction operating system to drive the pursuit of maximum value. The inclusion of a lean operating system would require only minor changes to the existing structure of a standard project alliancing agreement. Alliancing could essentially remain the same, both structurally and commercially, while incorporating Lean Construction methods and tools into its operating system. In the right circumstances, this combination could be used to deliver greater value to the client.
\end{abstract}

Keywords: Alliancing, Lean Construction, Operating System, Organisation, Commercial.

\section{INTRODUCTION}

Alves and Tsao (2007), through their study of IGLC papers from 2000 - 2006, identified that there has been a lack of research among the IGLC community in the area of relational contracting. They suggested that researchers "strive to understand how to implement relational contracting, measure its outcomes, and explain project results to help provide guidance to owners that are interested in working towards lean project delivery." (Alves and Tsao 2007, 57). Ten years later, there is still a gap in the literature comparing project alliancing (PA) and Lean Construction (LC). This paper contributes to addressing this issue by providing insight into the relationship between the PA and LC project delivery methods.

Previous work by the authors shows that alliancing does in fact inherently align with some key LC principles, particularly in four of the five LC principles identified by Diekmann et al. (2004), namely customer focus, culture and people, waste elimination, and

1 Graduate Research Assistant, NTNU - Norwegian University of Science and Technology, Trondheim, Norway, +4794431715, brendan@stud.ntnu.no

2 PhD Candidate, NTNU - Norwegian University of Science and Technology, Trondheim, Norway, +47 91309 166, ali.hosseini@ntnu.no

3 Associate Professor, NTNU - Norwegian University of Science and Technology, Trondheim, Norway, +47 73594 739, ola.ladre@ntnu.no 
continuous improvement. The research at that time lacked sufficient findings to show an alignment in the fifth principle of workplace standardization. To give a visual representation of the alignment between PA and LC we refer to the Lean Construction triangle in Figure 1.

There is sufficient evidence for PA and LC alignment concerning the organization and commercial sides of the triangle. Alliancing is associated with the principle of customer focus, a key element of the commercial side of the triangle. On the organizational side, we have shown alignment in the areas of culture/people, waste elimination and continuous improvement. The research

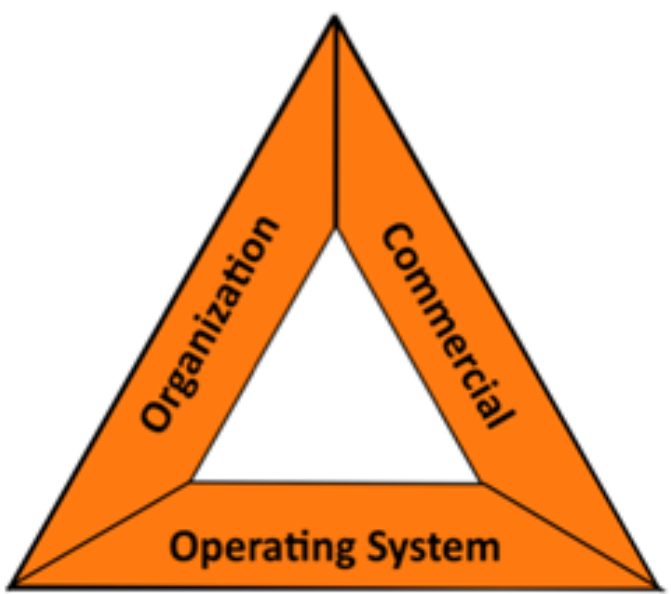

Figure 1: The Lean Construction Institute Triangle (Lean Construction Institute and Thomsen et al. (2009)) uncovered insufficient evidence to comment on the alignment between the operating system side of the triangle and is therefore the departure point for this paper.

There is a view that despite a lack of direct influence from alliancing, Integrated Project Delivery (IPD) can be seen as a combination of an alliance contract and governance system with a LC operating system (Raisbeck et al. 2010). Since IPD developed independently from alliancing yet resembles a combination of PA and LC, what would the potential outcomes be if PA and LC were combined intentionally? The fact that there is an inherent alignment between the organizational and commercial domains shows that such a combination is plausible, while the existence of IPD shows that it is possible.

The initial findings identified that a possible key difference between PA and LC appears in the operating system. Alliancing seems to lack the workplace standardization and the use of tools associated with LC. This paper will expand on this point by focusing in on the operating system side of the triangle. To provide a clear focus, the following research questions were identified:

- What are the similarities and differences between the two project delivery methods?

- Is there potential for the two systems to learn from each other?

Thomsen et al. (2009) uses the above triangle to represent the three domains of all project delivery systems. Domains must be in alignment and balanced to ensure that the delivery system is coherent and optimal. Using this model as a departure point, the paper begins by exploring the balance and alignment between these three domains for both PA and LC. Once a high-level understanding of each of these methods is established, a deeper exploration is made into their operating systems. This exploration forms the basis for a comparison between the PA and LC operating systems, noting any key differences and similarities between the two. Finally, conclusions are drawn and recommendations made for further research.

\section{METHOD}

A literature search was undertaken following the five steps prescribed by Blumberg et al. (2014). Step 1 was to define the questions to be answered after the literature search. Step 2 and 3 was to identify and apply key search terms in primary sources (for example 
databases and search engines). In step 4, secondary sources were located and reviewed (for example by scanning references). Step 5 was to evaluate the sources and the content. After this search, a review of the literature formed the basis for the theoretical background. To gain insight into both the academic and practical aspects of the operating systems, findings from both journal articles and conference papers (mostly primary sources) are used in combination with findings from government and industry publications (mostly secondary sources).

After the literature review, two of the authors undertook a series of 27 semi-structured in-depth interviews - following the descriptions of (Yin 2013) - in Australia in early 2016. The interview questions were formulated after the literature review was almost finished, and each interviewee received a transcript afterwards to avoid misunderstandings.

A document study was carried out after the literature search and interviews, where the documents were what (Weber 1990) denotes as sampling population. The purpose of this document study was to supplement the secondary sources found during the literature search. The main source for identifying relevant documentation were the interviewees, who both recommended and provided documents.

\section{THEORETICAL BACKGROUND}

In order to draw conclusions on the similarities and differences between PA and LC, an exploration of the current theory on each topic was undertaken. As the adoption of both alliancing and lean in the construction industry has become more prevalent, an understanding of the lean principles inherent in alliancing could be valuable to practitioners looking at adopting lean project delivery. Many countries, particularly in Europe, have started adopting alliancing in recent years. In addition, Finland, who adopted alliancing in 2007, has begun experimenting with adopting lean ideology into their alliance projects (Petäjäniemi and Lahdenperä 2012). The authors will explore the practical findings based on the outcome of this combination of lean and alliancing in Finland in later publications once enough completed projects are available to provide significant findings. A clear understanding of the current similarities between PA and LC from a theoretical view could help improve this adoption and could potentially lead to the creation of improved project delivery models.

IPD is a method used mostly in the USA that has many similarities to alliancing, with the one major difference that IPD incorporates a number of LC elements (Lahdenperä 2012; Raisbeck et al. 2010). IPD's use is mostly concentrated in America, yet the principles of lean are more prevalent worldwide. Alliancing is often considered at the top end of collaborative and relational contracting (Ross 2003) and is more widely distributed across the globe (Chen et al. 2012; Ingirige and Sexton 2006). In addition, IPD and Alliancing have often been used for different types of projects (Lahdenperä 2012). The authors believe that there is sufficient difference between alliancing and IPD to warrant such a study, and as such, a full exploration into the differences between IPD and alliancing will not be explored further in this paper but can be found in the studies by Lahdenperä (2012) and Raisbeck et al. (2010).

\subsection{Project Alliancing}

PA is a collaboration between a client, service providers and contractors where they share and manage the risks of the project together (Chen et al. 2010). All parties' expectations and commercial arrangements are aligned with the project outcomes and the project is driven by a best-for-project mindset, where all parties either win together, or lose together 
(Chen et al. 2012; Walker et al. 2013). The contract is designed around a non-adversarial legal and commercial framework with all disputes and conflicts resolved from within the alliance (Henneveld 2006). This type of project delivery can lead to improved project outcomes and value for money, in part due to the increased level of integration and cooperation between planners, design teams, contractors and operators (Love et al. 2010).

Alliancing as a model is well addressed in the literature and thus will not be discussed in great detail here. Previous research determined the most common characteristics of a project that may influence the decision to proceed with an alliance as the preferred PDM and provides an up-to-date look at the critical success factors and barriers to alliancing (Young et al. 2016a). Alliancing: A Participant's Guide is a detailed industry publication that addresses alliancing from the perspectives of both the owner and non-owner participants (NOP) (Morwood et al. 2008), and Introduction to Project Alliancing is a valuable piece of the alliancing body of knowledge (Ross 2003).

Project alliances are suitable - and most often used - for projects that have tight timeframes, multiple or complex stakeholder issues, are uncertain, complex and/or high risk (Young et al. 2016a). The organization domain of PA focuses on the high level of team integration necessary to deal with such projects. Alliancing uses a fully integrated project team that is co-located (in most cases) for the entire duration of the project. A board made up of equal representation of senior leaders from each party, known as the alliance leadership team (ALT), governs the alliance. The ALT makes decisions unanimously and handles all disputes (that cannot be handled at the management level) in house (with the exception of willful default), reinforcing the high level of team integration. The level of integration experienced in alliancing is at such a level where an alliance essentially becomes a 'virtual' organization.

The commercial domain of alliancing is made up of, in large part, the three-limbed compensation model. In recent times, alliance contracts have been structured around the three-limbed approach: (Ross 2003; Walker et al. 2015):

- Limb 1: all the directly reimbursable costs including project-specific overheads.

- Limb 2: corporate overheads and profit for each NOP, determined by an independent auditor and is placed 'at-risk' according to the pain/gain arrangement.

- Limb 3: incentivized cost-reimbursement where all participants share in the pain/gain associated with how the alliance performs against pre-arranged targets in cost (e.g. the target outturn cost and non-cost key result areas).

This three-limbed model creates a contractual alignment between all parties and provides the financial mechanisms that align the client and NOPs' interests and objectives.

The operating system of alliancing isn't known to be associated with a specific set of tools in the way that LC is. In a general sense, alliancing can be seen to behave in a similar way that a design and construct (D\&C) project would (Marosszeky and Ward 2010) by using common project management (PM) methods and tools. On a day-to-day level the alliance is run by an alliance management team (AMT), whose responsibility is to work with the alliance manager to drive the operational project delivery (Morwood et al. 2008). The authors are yet to see any prescriptions in the literature explicitly dictating how to operate an alliance. The literature often deals with what to achieve, i.e., the clients value for money statement, delivery of project objectives etc., but not how to achieve it. It seems that alliances do in fact rely on common PM methods and tools unspecific to any particular PDM. Given the extent to which common PM methods and tools are prevalent in the construction industry, they will not be covered in detail here. 


\subsection{Lean Construction}

Lean Construction was born out of the success of the lean philosophy that developed in the manufacturing industry. Both lean and the development of LC are well described in literature [Lean: (Ballard et al. 2001; Diekmann et al. 2004; Krafcik 1988; Liker 2004) and LC: (Howell and Ballard 1998; Howell 1999; Koskela 1992; Picchi 2001)]. Therefore, this information will not be covered. This paper will instead focus on the way LC addresses and balances the three domains of the LC triangle.

LC addresses the domain of project organization through the promotion of an integrated organization, the creation of cross-functional teams and the alignment of participants' interests. LC aims to break down the barriers between different organizations, and between the different functional silos that are present within most organizations. The organizations can reduce waste by avoiding the separation of design and construction and the sequential nature of processes often found in traditional project delivery. The alignment of interests is achieved by combining the promotion of collaboration with a major focus on the achievement of value as defined by the customers (both internal and external). This alignment extends not only to the alignment of different organizational objectives but also to the alignment of employees to each other and their own organizations (Azari-Najafabadi et al. 2011).

A key element of the LC operating system is characterized by the use of tools. While a tool in and of itself cannot be described as LC, the application and use of tools in a project embodies LC if it eliminates waste and/or maximizes value in the project. The same tools applied poorly could lead to the opposite effect by creating waste and not value (Thomsen et al. 2009). A number of tools have developed out of the lean community that have been employed in construction projects. These include, but are not limited to: Last Planner System $^{\mathrm{TM}}$, Increased Visualization, 5S Process, First Run Studies, Daily Huddle Meetings, Fail Safe for Quality and Safety, Plan-Do-Check-Act, A3 Reports, Value Stream Mapping and Target Value Design (Salem et al. 2005; Thomsen et al. 2009).

Addressing the commercial domain is not so straight forward since LC itself is not considered to be a typical project delivery contract strategy. The commercial domain has do to with the "compensation method, contractual assignment of roles and responsibilities, and financial mechanisms which can result in alignment of interests within a project organization, if properly designed, etc." (Azari-Najafabadi et al. 2011, 428). The research has uncovered many ways that LC can lead to alignment of interests within a project, but not in the specific commercial aspects of a compensation model or financial mechanism. This gap is often where, in the LC community, IPD steps in to handle the commercial contractual arrangements.

\section{FINDINGS AND DISCUSSION}

This discussion presents the authors' interpretation of the findings that have resulted from this research. This discussion explores the three project delivery domains of both PA and LC in order to determine the similarities and differences between the two and to identify the potential for lessons learned to be passed from one to the other and vice versa.

Alliancing is structured in a way that creates full alignment of the three domains. The shared risk and pain/gain arrangements combined with the alignment of client and commercial participants' objectives creates an entity that is adept at dealing with projects that are high risk or have high levels of uncertainty. When combined with unanimous decision-making, no dispute clause and open book, it helps to promote the win-win 
principle of PA necessary to deal effectively with issues that arise. When problems arise, it is in the best interest of all parties to find the best-for-project outcome, and find it quickly. The full integration of the organizational domain combined the commercial aspects creates a situation where the emphasis of contract management in the typical sense is removed and full focus can be placed on the operation of the alliance.

It seems that, even with a good balance between the domains, alliancing hasn't made any leaps forward in terms of revolutionizing its operating system when compared to traditional PDMs. The success of alliancing seems to be due to the innovations made in the organizational and commercial domains. Such a finding leads the authors to believe that alliancing could be greatly improved by focusing on its operating system.

LC as a method of management seems to operate mostly in the organizational and operating system domains. Despite deficiencies in what is commonly understood to be the commercial domain, LC maintains a high-level alignment between the other two domains. This alignment makes it particularly adaptable to being incorporated into a wide range of commercial models.

Considering both PA and LC from this perspective, we can see that they are highly compatible. They share many similarities in the organization domain in that they both strive to achieve full integration to the effect that value is maximized for the client. PA has a fully functioning commercial domain that is inherently aligned with the principles of LC (Young et al. 2016b), thus making PA and LC highly compatible in this area. In the operating system domain, PA relies on traditional approaches to project management and does not have a specific set of prescribed methods and tools of its own. This void creates a situation where a full LC operating system, i.e., tools and methods such as LPS, Increased Visualization, 5S etc., could be seamlessly introduced into an alliance without fundamentally changing the alliance itself.

The findings show that there is great potential for PA and LC to learn from each other. This possibility has been demonstrated practically via the adoption of alliance-like governance and commercial aspects into LC, creating the IPD model. On the other hand, the alliancing model could benefit from LC, particularly from its operating system, while still staying true to the structure and principles that make alliancing what it is today.

\section{CONCLUSIONS}

A major driver of alliancing is to deliver value for money to the client, so it comes as a surprise that, to this date, alliancing it yet to fully capitalize on the LC operating system to drive the pursuit towards maximum value. Despite the presence of PDMs that resemble a combination of PA and LC, namely IPD, alliancing, in its own right, has solidified its place alongside such PDMs in the project delivery toolkit available to clients. The presence of IPD does not make alliancing obsolete and the inclusion of a LC operating system into standard PA would not necessarily become IPD either.

Regarding the similarities and differences between the two project delivery methods, the similarities are in the organizational domain while differences exist on the commercial and operating system domains. Despite the differences in the commercial domains, PA does inherently align with LC principles, making the two compatible in this area. The major difference in the operating system domain is that LC relies on a specific set of tools to handle daily operations while PA uses non-specific tools from the common PM toolkit.

There is potential for the two systems to learn from each other. Particularly, alliancing could learn from the LC operating system. The inclusion of a lean operating system would not require any major changes to the existing structure of a standard PA agreement. 
Alliancing could essentially remain the same, structurally and commercially, while incorporating LC methods and tools into its operating system. This integration is made possible due to the inherent alignment between alliancing and the lean construction principles in the organizational and commercial domains.

The authors aim to study the practical implications of this concept by reviewing the outcomes of a number of Finnish alliances that are in the process of experimenting with the inclusion of the lean construction philosophy, tools and methods. Based on these theoretical findings, the expectation is that this implementation will deliver positive results and key lessons learned.

\section{REFERENCES}

Alves, T., and Tsao, C. (2007). "Lean construction-2000 to 2006." Lean Construction Journal, 46.

Azari-Najafabadi, R., Ballard, G., Cho, S., and Kim, Y.-W. (2011). "A dream of ideal project delivery system." Proc. of The Architectural Engineering Conference (AEI)Building Integrated Solutions, 427-436.

Ballard, G., Koskela, L., Howell, G., and Zabelle, T. (2001). "Production system design: Work structuring revisited." White Paper, 11.

Blumberg, B. F., Cooper, D. R., and Schindler, P. S. (2014). Business research methods, McGraw-hill education.

Chen, G., Zhang, G., Xie, Y.-M., and Jin, X.-H. (2012). "Overview of alliancing research and practice in the construction industry." Architectural Engineering and Design Management, 8(2), 103-119.

Chen, G., Zhang, G., and Xie, Y. (2010). "Overview of the Australia-based studies on project alliancing." Proceeding of the Australiasian Universities Building Education Association (AUBEA), 35th Annual Conference, 1-15.

Diekmann, J. E., Krewedl, M., Balonick, J., Stewart, T., and Wonis, S. (2004). "Application of Lean Manufacturing Principles to Construction." The Construction Industry Institute, Austin, Texas.

Henneveld, M. (2006). "Alliance Contracting--Removing the Boundaries for Infrastructure Delivery." Annual Conference \& Exhibition of the Transportation Association of Canada.

Howell, G., and Ballard, G. (1998). "Implementing lean construction: understanding and action." Proc. 6 th Ann. Conf. Intl. Group for Lean Constr.

Howell, G. A. (1999). "What is lean construction-1999." Proc. Ann. Conf. Intl. Group for Lean Constr, Citeseer, 1.

Ingirige, B., and Sexton, M. (2006). "Alliances in construction: investigating initiatives and barriers for long-term collaboration." Engineering, Construction and Architectural Management, 13(5), 521-535.

Koskela, L. (1992). Application of the new production philosophy to construction, Stanford University Stanford, CA.

Krafcik, J. F. (1988). "Triumph of the lean production system." MIT Sloan Management Review, 30(1), 41.

Lahdenperä, P. (2012). "Making sense of the multi-party contractual arrangements of project partnering, project alliancing and integrated project delivery." Construction Management and Economics, 30(1), 57-79.

Liker, J. K. (2004). The Toyota Way: 14 Management Principles from the World's Greatest Manufacturer, McGraw-Hill, New York. 
Love, P. E., Mistry, D., and Davis, P. R. (2010). "Price competitive alliance projects: identification of success factors for public clients." Journal of Construction Engineering and Management.

Marosszeky, M., and Ward, M. (2010). "Public Sector Experience with the Use of KRA and KPI Frameworks onAlliances - to Incentivise Performance in Non-cost areas of Delivery." Evans and Peck.

Morwood, R., Scott, D., and Pitcher, I. (2008). "Alliancing: A Participant's Guide." Published by Maunsell AECOM.

Petäjäniemi, P., and Lahdenperä, P. (2012). "Alliance contracting-one for all and all for one (Finland)." European Infrastructure Procurement Symposium, Conflict between Institutional Frameworks and Managerial Project Practice.

Picchi, F. A. (2001). "System view of lean construction application opportunities." Proc. Ann. Conf. Intl. Group for Lean Constr, 39-50.

Raisbeck, P., Millie, R., and Maher, A. (2010). "Assessing integrated project delivery: a comparative analysis of IPD and alliance contracting procurement routes." Management, 1019, 1028.

Ross, J. (2003). "Introduction to project alliancing." Alliance Contracting Conference.

Salem, O., Solomon, J., Genaidy, A., and Luegring, M. (2005). "Site implementation and assessment of lean construction techniques." Lean Construction Journal, 2(2), 121.

Thomsen, C., Darrington, J., Dunne, D., and Lichtig, W. (2009). "Managing integrated project delivery." Construction Management Association of America (CMAA), McLean, VA, 105.

Walker, D., Harley, J., and Mills, A. (2013). "Longitudinal Study of Performance in Large Australasian Public Sector Infrastructure Alliances." RMIT University, Melbourne, Victoria.

Walker, D. H. T., Harley, J., and Mills, A. (2015). "Performance of project alliancing in Australasia: a digest of infrastructure development from 2008 to 2013." Construction Economics and Building, 15(1), 1-18.

Weber, R. P. (1990). Basic content analysis, Sage.

Yin, R. K. (2013). Case study research: Design and methods, Sage publications.

Young, B. K., Hosseini, A., and Lædre, O. (2016a). "The Characteristics of Australian Infrastructure Alliance Projects." Energy Procedia(96), 833-844.

Young, B. K., Hosseini, A., and Lædre, O. (2016b). "Project Alliances and Lean Construction Principles." 24th Annual Conference of the International Group for Lean Construction Boston, USA. 